
allemande

50-1| 2018

Regards franco-allemands sur la justice dans la construction européenne | Les élections législatives de 2017 en Allemagne et en Autriche

\title{
Karine LE BAIL, La musique au pas. Être musicien sous l'Occupation
}

Paris, CNRS Éditions, 2016

Robert Weeda

\section{(2) OpenEdition}

Journals

\section{Édition électronique}

URL : https://journals.openedition.org/allemagne/722

DOI : 10.4000/allemagne.722

ISSN : 2605-7913

Éditeur

Société d'études allemandes

Édition imprimée

Date de publication : 30 juin 2018

Pagination : 216-219

ISSN : 0035-0974

Référence électronique

Robert Weeda, "Karine Le BAIL, La musique au pas. Être musicien sous I'Occupation », Revue d'Allemagne et des pays de langue allemande [En ligne], 50-1 | 2018, mis en ligne le 30 juin 2018, consulté le 02 juin 2022. URL : http://journals.openedition.org/allemagne/722 ; DOI : https://doi.org/10.4000/allemagne 722 
spécificités et les ressorts historiques de chaque situation nationale: citons l'étude d'Ute Gerhard consacrée au droit de la famille, celle de Malte König sur les effets de la Première Guerre mondiale, ou encore celle de Cornelia Möser concernant les débats autour du concept de genre au sein des milieux féministes.

Les textes sont répartis en quatre chapitres, traitant respectivement les mouvements de femmes et féminismes au XIXe siècle, le poids des deux guerres mondiales, le tournant des années 1970, et, sur la longue durée, l'éducation, la formation et les mondes du travail. Les lecteurs et lectrices à la fois francophones et germanophones apprécieront la diversité des thématiques abordées, incluant les positionnements féministes face à la prostitution, l'évolution des masculinités au sortir de la Deuxième Guerre mondiale, ou divers aspects de la présence des femmes dans le monde du travail. La dimension transnationale enfin s'avère particulièrement pertinente pour interroger les problématiques politiques actuelles, impossibles à réduire à la sphère nationale: c'est ce que soulignent les contributions de Valérie Dubslaff et de Dominique Herbet, qui examinent diverses facettes de l'antiféminisme contemporain, en relation avec les extrêmes droites françaises et allemandes. Leurs analyses rejoignent le constat fait par Cornelia Möser en conclusion de son article: en ces temps de tournants réactionnaires et face aux menaces pesant sur les idéaux démocratiques européens, il importe de redéfinir l'enjeu politique du féminisme pour en fortifier la capacité de réflexion et d'action, et le débarrasser de réflexes d'appartenance nationale toujours latents. Par ses apports à une histoire critique de "la condition féminine» et des mouvements féministes, cet ouvrage peut certainement contribuer à une telle mise au point.

Alice Primi

Karine LE BAIL, La musique au pas. Être musicien sous l'Occupation, Paris, CNRS Éditions, 2016, 439 p.

Même si le titre ne le précise pas, il s'agit bien d'une étude sur la scène musicale de la France entre 1940 et 1944, issue pour partie d'une thèse de doctorat réalisée sous la direction de Jean-Pierre Azéma et soutenue en 2015 à l'Institut d'études politiques de Paris. Comme l'auteure l'écrit dans l'«Épilogue» (p. 274), l'intention du livre est née d'une phrase de Bertolt Brecht écrivant en 1934 au compositeur Paul Hindemith que "La musique n'est pas une Arche de Noé qui puisse vous faire traverser sans dommage le déluge»; en effet, déluge il y a eu pour les musiciens sous l'Occupation.

La France vaincue de juin 1940 se trouve partagée en deux territoires (zone occupée et zone libre) - une situation unique dans l'Europe occupée - avec le maintien, en zone libre, d'un gouvernement français, installé à Vichy, jouissant d'une liberté d'action relative qui se confirmera rapidement dans la création de Radio-Vichy et sa scène musicale, et le choix de Marseille comme capitale culturelle de cette zone. Quant aux troupes allemandes présentes dans la zone occupée, elles seront affectées à la sécurité militaire et au maintien de l'ordre public, tout en étant chargées d'entraver aussi peu que possible la vie culturelle française, et en particulier celle de Paris avec ses lieux publics de concert et ses salons de musique.

Ayant choisi pour son étude de limiter son échelle d'analyse aux réseaux de production de la musique, l'auteure a retenu «trois grandes catégories de lieux» - en 
l'occurrence les différents espaces publics du concert (théâtres, orchestres, etc.), les salons, et la radio comme scène.

Dans la première partie, deux "scènes» sont à l'étude: une "scène» inventée par l'occupant sous l'impulsion d'Otto Abetz, qui doit préfigurer une nouvelle Europe des cultures, et une scène radiophonique ensuite, avec ses deux antennes, la radio allemande de langue française et la Radio-diffusion nationale.

En raison probablement de son affichage "francophile», Otto Abetz se voit octroyer par Hitler le statut d'ambassadeur allemand à Paris en novembre 1940. Grâce à sa profonde connaissance de la culture française, il mettra sur pied dans la capitale un Institut culturel allemand en s'efforçant de créer l'illusion d'une "scène partagée entre occupants et occupés» (p. 35). En réactivant la longue tradition d'échanges culturels entre les deux pays, Otto Abetz met alors en scène "l'idée européenne», "cette autre fable de la collaboration franco-allemande» ( $p$. 38): elle sera mise en valeur avec Ludwig van Beethoven dont les ceuvres seront régulièrement entendues sous la direction des meilleurs chefs français et étrangers. Sous sa responsabilité artistique, également, des tournées sont organisées avec les musiciens allemands - dont le «Reichsorchester" (l'Orchestre philharmonique de Berlin) qui se produira régulièrement jusqu'en septembre 1944.

Au nord de la ligne de démarcation est créée, avec l'aide de la Radio de Stuttgart et de ses propagandistes nazis, une nouvelle station francophone et de propagande: Radio-Paris. Otto Sonnen, pianiste d'une certaine renommée, sera chargé d'en diriger la section musicale. Mais, hormis l'équipe dirigeante arrivée directement de RadioStuttgart, le personnel au contact des artistes est désormais exclusivement français et c'est grâce à l'argent français que la station allemande peut engager les grandes formations de variétés parisiennes et les vedettes de la chanson. Naturellement, la propagande n'est jamais loin: elle est même constitutive du déploiement des programmes artistiques et, au fil des mois, on assiste à la montée en puissance des chroniques contre les juifs et les francs-maçons, avec un véritable tournant au printemps 1941 où Otto Sonnen annonce des actions visant à "anéantir l'influence juive dans les zones occupée et non occupée» (p. 53).

En zone libre, Radio-Vichy devient, dès l'automne 1940, un outil essentiel de propagande radiophonique et l'ensemble des services artistiques de la station sont installés à Marseille. S'ouvriront ainsi de nouvelles perspectives pour les artistes réfugiés dans cette zone. Mais face au réseau d'émetteurs puissant de Radio-Paris, la Radio de Vichy ne parvient pas à constituer un pôle culturel important ni devenir une radio de combat. Les artistes se demandent de quel côté de la ligne de démarcation ils doivent s'installer maintenant pour ne pas être traités de déserteurs. La question de la résistance ou de la collaboration de la part des musiciens français va devenir de plus en plus pressante: ainsi, doivent-ils éventuellement rejoindre les rangs du Grand Orchestre de Radio-Paris nouvellement créé en juillet de la même année dans le but d'affirmer la suprématie du génie allemand?

Dans la deuxième partie consacrée à Vichy, K. Le Bail montre comment l'idéologie en particulier antisémite - imprègne de plus en plus l'ensemble des programmes artistiques de Radio-Vichy installés à Marseille (avant de revenir à Paris en mars 1943). L'instrumentalisation de la grande musique sera révisée au printemps/été 1941 où le régime de Vichy décide de s'engager plus avant dans une politique de collaboration avec l'Allemagne: alors que dès l'automne 1941 se multiplient les attaques contre les juifs et la franc-maçonnerie, les services artistiques ne semblent pas réaliser l'enjeu d'une immixtion allemande dans les affaires françaises où, après une profonde refonte 
de la grille de la Radio, se prépare la réouverture des studios parisiens qui sonnera le glas de la politique de décentralisation entreprise par la Radio nationale. L'occupation allemande de la zone libre en novembre 1942 entraîne par ailleurs une radicalisation de la propagande radiophonique où Radio-Vichy devient l'auxiliaire de la traque des juifs qui s'abat sur tout le territoire, et le pouvoir politique assigne une nouvelle mission à la musique, celle de servir d'intermède entre les émissions politiques.

Dans le chapitre "Logiques et paradoxes de l'antisémitisme en musique», K. Le Bail rappelle que les ordonnances françaises de la loi du 3 octobre 1940 portant statut des juifs ont pour but de leur enlever toute influence politique, artistique et littéraire. Ainsi, pour les institutions culturelles, c'est toute une dialectique de l'obéissance et de la conscience qui se trouve clairement mise en jeu. Le premier administrateur culturel qui s'y voit confronté est Henri Rabaud, le directeur du Conservatoire (auquel l'auteure a déjà consacré une étude en 2010), remplacé en avril 1941 par Claude Delvincourt. Avec la nouvelle loi du 2 juin 1941, Vichy franchit une nouvelle étape dans le durcissement de sa politique antisémite. L'article 4 de la loi prévoit la limitation des juifs dans les professions libérales, donc aussi artistiques. Aucun élève juif ne doit désormais être maintenu ou admis au Conservatoire.

En quelque vingt pages (chapitre "La Radio, pivot de la politique antijuive de Vichy») sont ensuite décrits les atermoiements brouillons de Radio-Vichy et de sa tutelle dans la mise en application de la politique antijuive. L'auteure y retient trois axes principaux. L'extraordinaire imbroglio juridique d'abord, qui, généré par l'arsenal législatif approximatif de Vichy, donna lieu à une succession d'interprétations contradictoires et de cafouillages administratifs ajoutant au traitement inhumain du personnel artistique de la Radio. En deuxième, elle met en avant la vulnérabilité extrême des professions artistiques au sein de la Radiodiffusion nationale. Le troisième concerne le mode de prises de décisions quant à la musique juive et ses compositeurs. Durant l'Occupation, la présence de la musique de compositeurs juifs est continue et affichée sur les ondes de la Radiodiffusion nationale: Paul Dukas reste joué, tout comme Jacques Offenbach ou Felix Mendelssohn (du moins jusqu'en 1943), ou encore Giacomo Meyerbeer, un compositeur pourtant interdit en Allemagne. La "résistance par les œuvres» est la marque visible de l'action du milieu musical et littéraire durant l'Occupation.

Dans la troisième partie "Modes d'une résistance musicienne», Karine Le Bail essaie d'évaluer l'engagement musical dans les mille et une manières d' "entrer en résistance» face au régime allemand et sa démagogie antisémite. Au lieu de se lancer dans une approche théorique de l'engagement musicien, elle a préféré faire l'étude croisée de deux parcours singuliers: celui d'abord de la compositrice Elsa Barraine (1910-1999), fondatrice à l'automne 1941 de l'unique organisation de résistance spécifique aux musiciens, le "Comité de Front national de la musique». Ensuite, le parcours sinueux (déjà étudié par l'auteure dans un ouvrage paru en 2010) de l'ingénieur-preneur de son Pierre Schaeffer (1910-1995). Cet individu seul et "engagé»-d'abord dans les rouages du régime de Vichy - devient, en 1943, I'une des figures centrales de la résistance à la Radio (de l'État français) jusqu'à son action décisive à la tête du Studio d'essai dans la libération des ondes d'août 1944 (qui verra la création de la RTF).

"La musique épurée» est la dernière partie de l'ouvrage. Elle permet à l'auteure de dresser un premier bilan du délicat procès d'épuration des collaborateurs (et antisémites). Édictée le 26 août 1944, une ordonnance introduit un nouveau crime dans le droit français, le crime d'indignité, qu'elle a assorti d'une nouvelle peine, la dégradation nationale; complétée le 26 décembre 1944, cette ordonnance s'impose naturellement comme le grand texte normatif de l'épuration intellectuelle et artistique. 
La collaboration musicale appelle des sanctions exemplaires. Qui sont ces musiciens qu'il faut juger de crime d'indignité? L'auteure cite le nom du pianiste Alfred Cortot rencontré plus d'une fois dans les parties précédentes de l'ouvrage, ainsi que celui de Jean Fournet, chef du Grand Orchestre de Radio-Paris. Elle nous introduit aussi au traitement des dossiers de deux musiciennes, la cantatrice Germaine Lubin et la chanteuse Léo Marjane.

Les premières mesures prises par le gouvernement avec ces ordonnances de fin 1944 ne suffisent pas à traiter toutes les questions liées aux industries du spectacle. Ainsi sera décidé de la mise en place d'une Commission d'épuration des gens du spectacle (CGES), mais elle est chaotique, et ses décisions suscitent l'indignation. Pour remédier à cette situation, la CGES est remplacée par deux Comités nationaux, des instances dédiées l'une aux interprètes, l'autre aux créateurs. Leur travail respectif est sévèrement jugé. Dans ce paysage toujours chaotique, la Radio est tentée d'inventer ses propres modalités d'épuration dont les conclusions seront, finalement, rapportées aux jugements des Comités nationaux. Il y eut certes quelques réflexes d'indulgence à l'endroit des musiciens de renom compromis dans la collaboration. Et K. Le Bail rappelle ici le cas d'André Cluytens, d'origine belge, à la tête de l'Orchestre de la Société des concerts du Conservatoire de Paris. Pourtant, "l'épuration judiciaire buta sur la question du signifiant de la musique, et partant, de sa responsabilité» (p. 270). Dans un espace public saturé de prises de position passionnées autour de la responsabilité et du devoir d'engagement des écrivains et des intellectuels, les musiciens ne représentèrent finalement qu'un bien faible enjeu politique.

Cet ouvrage témoigne d'une remarquable culture socio-historique et d'une approche philosophique nourries par une recherche très approfondie (exhaustivité des sources utilisées - tant françaises qu'allemandes -, archives publiques et privées, mémoires et témoignages individuels utilisés par l'auteure) qui fait honneur à l'objet de son étude.

Robert Weeda

Sandrine FUSS NIKOLIĆ, La vie musicale strasbourgeoise à l'ombre de la croix gammée, Strasbourg, Jérôme Do Bentzinger, 2015, 396 p.

Avec cet ouvrage, l'auteure reprend le texte de sa thèse de doctorat soutenue à l'Université de Bâle. Cette étude s'intéresse en particulier à la capitale alsacienne lors de son annexion (de fait) par l'Allemagne de 1940 à 1944. L'objectif de Sandrine Fuss Nikolić est de "donner une vision sur la manière dont la culture musicale nazie a pu apprivoiser et influencer les masses» (p. 359) "grâce à un investissement financier important de l'administration allemande, à une bonne gestion des ressources humaines et à une propagande adroitement utilisée» (p. 360).

La première partie du portrait musical de Strasbourg durant l'annexion est consacrée au théâtre et à l'orchestre. La direction de l'orchestre et du théâtre est confiée, dès le 7 août 1940, au chef de l'administration civile, le Gauleiter Robert Wagner également responsable des affaires financières en lieu et place du ministère correspondant dans le Reich. "La rapidité avec laquelle les affaires du théâtre sont prises en main par l'occupant [...] est la preuve tangible de l'importance du rôle politique que les Allemands accordent à la culture» (p. 31). Mais la restauration tant nécessaire du bâtiment suite aux dégâts causés par la guerre prendra du temps et ne sera 